Atos de Pesquisa em Educação - ISSN 1809-0354

Blumenau, v.14, n.2, supl.1, p.772-791, out./nov. 2019

DOI: http://dx.doi.org/10.7867/1809-0354.2019v14n2s1p772-791

\title{
PORTFÓLIOS REFLEXIVOS E ESCRITA DE SI: O QUE REVELAM AS CRIANÇAS?
}

\section{REFLECTIVE PORTFOLIOS AND THE WRITING OF THE SELF: WHAT DO CHILDREN REVEAL?}

\section{PORTAFOLIOS REFLEXIVOS Y LA ESCRITURA DE SI: ¿QUÉ REVELAN LOS NIÑOS?}

\author{
SIMAS, Vanessa França \\ vanessafsimas@gmail.com \\ UNICAMP - Universidade Estadual de Campinas \\ https://orcid.org/0000-0002-4250-3277 \\ PRADO, Guilherme do Val Toledo \\ gvptoledo@gmail.com \\ UNICAMP - Universidade Estadual de Campinas \\ https://orcid.org/0000-0002-2415-8369
}

\begin{abstract}
RESUMO Este artigo é sobre portfólios reflexivos construídos por crianças de um primeiro ano do ensino fundamental e tem por objetivo alcançar a potencialidade do uso de portfólios reflexivos nessa etapa da educação básica. Os dados são os portfólios produzidos pelas crianças. Analisa-se o que evidenciam em seus portfólios e como ocorre o movimento reflexivo sobre si e sobre a própria aprendizagem. A escrita nos portfólios revelou que a sua construção possibilitou reflexões discentes, produção de sentidos, buscas por estabelecer relações, exercícios de metacognição e avaliações da aprendizagem e do ensino. Ademais, quando os alunos revelaram os sentidos que atribuiam às propostas didáticas, eles possibilitaram à professora uma reorganização da prática em favor dos aprendizados das crianças.
\end{abstract}

Palavras-chave: Avaliação do ensino. Construção de sentido. Portfólio do aluno. Reflexão.

ABSTRACT This article is about reflective portfolios constructed by children attending the first year of elementary school. It is about a case study whose aim is to build understanding of what the writing that the students produce reveals to themselves and to the teacher. The data is made up of portfolios produced by children. The analyzes are on what children show in their portfolios and how the reflexive movement occurs about themselves and about their own learning. The writing of the children in the portfolios revealed that its construction made possible student's reflections, sense production, search for making connections, metacognition exercises, and assessments of learning and teaching. In addition, when the students revealed the meaning they attributed to the didactic proposals, they enabled the teacher to reorganize the practice in favor of the children's learning. Keywords: Teaching assessment. Sense construction. Student Portfolio. Reflection.

RESUMEN Este artículo es sobre portafolios reflexivos construidos por niños de un primer año de enseñanza primaria. Se trata de un estudio de caso cuyo objetivo es 
construir comprensiones acerca de lo que la escritura que los alumnos producen revela a ellos mismos y a la profesora. Los datos son los portafolios producidos por los niños. Se analiza lo que evidencian en sus portafolios y cómo ocurre el movimiento reflexivo sobre sí y sobre el propio aprendizaje. La escritura en los portafolios mostró que su construcción posibilitó reflexiones discentes, producción de sentidos, búsquedas por establecer relaciones, metacognición y evaluaciones del aprendizaje y de la enseñanza. Además, cuando los alumnos revelaran los sentidos que atribuyeron a las propuestas didácticas, ellos posibilitaran a la profesora una reorganización de la práctica en favor de los aprendizajes de los niños.

Palabras-clave: Construcción del sentido. Evaluación de la enseñanza. Portafolios del alumno. Reflexión.

\section{PORTFÓLIOS REFLEXIVOS: UMA INTRODUÇÃO}

Originalmente o portfólio surge no campo da arte, partindo de uma modalidade de avaliação. Naquele contexto, esse instrumento consistia em uma pasta em que os artistas depositavam as suas obras mais relevantes (HERNÁNDEZ, 2000; VILLAS BOAS, 2004; ALARCÃO, 2010). Através dessas pastas era possível conhecer a trajetória do profissional, já que elas apresentavam uma visão geral de momentos marcantes, bem como da totalidade de suas obras.

Somente no início da década de noventa o uso dos portfólios passou a existir também na área educacional. Essa aparição coincide com o período em que algumas mudanças em relação às concepções de ensino e aprendizagem estavam em curso: tornava-se necessário que ao invés de reter informações os sujeitos conseguissem utilizá-las em diversas situações; era importante a utilização de estratégias na resolução de problemas e não mais decorar fórmulas; o processo passou a ser mais importante do que o resultado; e começou-se a valorizar a capacidade de buscar, organizar e interpretar a informação e não mais a quantidade (HERNÁNDEZ, 2000). Foi nesse cenário que o portfólio passou a configurar-se como um meio de evidenciar os processos de aprendizados no âmbito da avaliação educacional, possibilitando uma avaliação formativa e não mais tradicional, centrada também nos processos de aprendizagem e não somente nos seus produtos.

Apesar da avaliação do ensino e da avaliação da aprendizagem serem aspectos analisados neste artigo, utilizaremos aqui o conceito de portfólio reflexivo, elaborado por Idália Sá-Chaves $(2004,2005)$, e não o conceito original. Nos 
portfólios reflexivos não é a avaliação (a partir do olhar sobre a pasta e sobre o desenvolvimento dos trabalhos) o foco principal, mas sim o fato da sua produção promover o desenvolvimento metacognitivo do autor. Isso ocorre porque, ao selecionar e refletir sobre aquilo que compõe o portfólio, o sujeito é capaz de monitorar o próprio conhecimento e desenvolver a escrita de si como maneira de organizar o pensamento e a aprendizagem (SÁ-CHAVES, 2005).

Os muitos enfoques do portfólio - formativo, pois permite ao sujeito entender evidências que podem ser centro de interesse para o processo de formação; continuado, pois é uma construção contínua e frequente; reflexivo, uma vez que ao optar sobre o que vai compor o portfólio e ao pensar no porquê dessa escolha, o sujeito reflete; compreensivo, já que representa a compreensão integradora entre teoria e prática (SÁ-CHAVES, 2004) - auxiliam o desenvolvimento dessa metacognição. A autora ainda enfatiza que o portfólio é

[...] uma peça única no sentido de criação de autor e permite o acesso não apenas aos conhecimentos por si evidenciados, mas sobretudo aos significados que 0 autor lhes atribui $e$ às circunstâncias que, ecologicamente, configuram e permitem compreender o modo como esses mesmos significados se constroem e interferem na reconfiguração das suas próprias identidades (SÁ-CHAVES, 2005, p. 9).

Partindo desse aspecto - o fato da construção do portfólio revelar os sentidos que os educandos atribuem às propostas e à autoavaliação que realizam - Shores e Grace (2001) consideram que o desenvolvimento desse instrumento é um tipo de pesquisa ativa ou de pesquisa de sala de aula. Isso porque, ao ter acesso a esses sentidos, a professora ${ }^{1}$, além de perceber o desenvolvimento das crianças, tem a possibilidade de avaliar, de maneira mais potente (pois passa a acessar evidências do que pensam as crianças sobre as propostas e sobre as maneiras de aprender) seu desempenho e planejar aulas atendendo às demandas coletivas e particulares que aparecem nos enunciados presentes nos portfólios.

Hernández (2000) e Villas Boas (2004, 2005), apesar de tratarem também do portfólio como um meio de autoavaliação, ressaltam aspectos reflexivos desse instrumento. Esses aspectos revelados pelos autores podem ser apontados nas

\footnotetext{
${ }_{1}^{1}$ Optamos, neste artigo, por utilizar o feminino para dizer das professoras e dos professores, uma vez que entendemos que a maioria desses profissionais é composta por mulheres.
} 
caracterizações que fazem da construção dos portfólios: nesse processo os educandos tentam estabelecer "coerência às atividades de ensino com as finalidades de aprendizagem" (HERNÁNDEZ, 2000, p. 165); o instrumento favorece a criatividade e a organização dos pensamentos, uma vez que a sua construção está submetida à criança, que pode usar da linguagem que eleger mais adequada para elaborá-lo (VILLAS-BOAS, 2004); sua construção apoia-se em seis princípios "construção, reflexão, criatividade, parceria, autoavaliação e autonomia" (VILLASBOAS, 2004, p. 135).

Dessa maneira, entendemos necessário ressaltar que apesar de neste artigo usarmos o termo portfólios reflexivos, referido por Sá-Chaves (2004, 2005), reconhecemos a colaboração de muitos outros autores na compreensão do conceito utilizado.

\section{OS PORTFÓLIOS REFLEXIVOS E A APRENDIZAGEM}

A perspectiva de sujeito assumida neste trabalho é a que parte dos pressupostos da abordagem sócio-histórica, bem como de aportes do pensamento do círculo bakhtiniano. Consideramos que os sujeitos se constituem no contato com o meio e com o outro, através da linguagem, como tão bem indicou Vigotski (2007, 2008). Outros autores que também coadunam com essa perspectiva constitutiva dos sujeitos pela linguagem são os participantes do Círculo de Bakhtin, compreendendo os sujeitos, nesse contexto linguageiro, como sujeitos dialógicos.

Se as pessoas aprendem em contato com o outro e com o meio, mediados e constituídos pela e na linguagem, podemos dizer que no campo educacional é de extrema relevância que o discente faça uma relação do conteúdo que lhe é ensinado com a realidade em que vive em diálogo com os outros (incluímos aqui também a docente), para que os conhecimentos passem a ter sentidos para ele, possibilitando, assim, aprendizagens significativas, ao invés da mera reprodução de conhecimentos.

As aprendizagens ocorrem também através da mediação, já que sempre em contato com o meio e os outros. É essa mediação que colabora no percurso em que os conceitos interpsíquicos se tornam intrapsíquicos, ou seja, internalizam-se 
(VIGOTSKI, 2007, 2008). Vigotski acreditava que sempre há uma reconstrução, uma reelaboração, por parte do homem, dos significados que the são transmitidos pelo grupo social em que está inserido. Nesse mesmo viés, Sobral, ao dizer da ideia de diálogo em Bakhtin, anuncia que esta é:

[...] principalmente a descrição de um lugar de tensões, uma 'arena de vozes', um campo de luta, de confronto entre diferenças, estando seu aspecto principal no fato de que somos seres relacionais, seres que vivem e se constituem nas relações uns com os outros, que se formam nos diálogos que travam ao longo da vida, seja qual for sua natureza, e de que o sentido nasce da diferença (SOBRAL, 2009, p. 8).

Se as aprendizagens ocorrem através da mediação; se o diálogo, mais do que harmonia, é arena de vozes, campo de luta, de exposição das diferenças; e se somos, por natureza, seres dialógicos, compreendemos que em diversas dimensões da consciência humana haverá sempre reconstrução e reelaboração dos significados transmitidos (VIGOTSKI, 2007) e, ainda, que a vida na escola, em coletivo, será sempre uma arena de vozes, um lugar de tensões e conflitos na construção de significados e sentidos partilhados por essa comunidade de linguagem.

Importante, portanto, escutar as vozes presentes nessa arena, entender como elas podem vir a ajudar a professora em sua prática de ensino, compreender como todas elas constituem a escola e que precisam ser consideradas no planejamento das aulas, no projeto político pedagógico, no contexto da comunidade escolar. Por isso a relevância de pensar em meios (neste caso particular, os portfólios) que potencializem maneiras com que essas vozes sejam cada vez mais percebidas e compreendidas pelas profissionais da educação.

Os atos de refletir e dizer de si na construção do portfólio reflexivo, também podem potencializar o desenvolvimento de conceitos (VIGOTSKI, 2008). Ao explicar que esse desenvolvimento de conceito ${ }^{2}$ ou do significado das palavras pressupõe uma série de funções intelectuais - como por exemplo: atenção, memória, capacidade para comparar e diferenciar - Vigotski cita Tolstói para esclarecer que o

\footnotetext{
${ }^{2}$ Segundo Vigotski (2008, p. 104) o conceito "é mais do que a soma de certas conexões associativas formadas pela memória (...) é um ato real e complexo de pensamento que não pode ser ensinado por meio de treinamento...".
} 
ensino direto de conceitos não é possível. Exemplifica seu argumento ao trazer o fato que Tolstói queria ensinar a um grupo de crianças camponesas a linguagem literária, porém por repetição, explicações e memorização essas crianças não aprenderam. Tolstói explica que a criança precisa de oportunidades para adquirir novos conceitos e palavras a partir do contexto linguístico geral.

Quando ela ouve ou lê uma palavra desconhecida numa frase, de resto compreensível, e a lê novamente em outra frase, começa a ter uma ideia vaga do novo conceito: mais cedo ou mais tarde ela sentirá a necessidade de usar essa palavra - e uma vez que a tenha usado, a palavra e o conceito the pertencem... Mas transmitir deliberadamente novos conceitos ao aluno... é, estou convencido, tão impossível e inútil quanto ensinar uma criança a andar apenas por meio das leis do equilíbrio (TOLSTÓl apud VIGOTSKI, 2008, p. 105).

Entendemos aqui o portfólio reflexivo também como um mediador, não um mediador que leve a criança a memorizar conceitos, mas que favoreça reflexões para que construa novos conceitos. Compreendemo-lo como um mediador que potencializa o processo reflexivo da criança, levando-a a realizar uma relação do conteúdo que the é ensinado com a realidade em que vive. Como instrumento mediador, o portfólio reflexivo ainda auxilia no movimento de internalizar os conceitos já que, ao pensarem sobre e justificarem suas escolhas, os educandos reelaboram os significados que lhes foram transmitidos.

Sabendo da necessidade de escutar as vozes dos educandos, percebemos o portfólio como meio potente para que essas vozes se mostrem de uma maneira outra, de uma maneira que revele os sentidos que as crianças atribuem às propostas realizadas, a si mesmas e ao ensino praticado pela professora.

Partindo desses pressupostos, o foco principal deste artigo, já mencionado anteriormente, consiste em construir compreensões acerca do que a escrita que as crianças produzem ao construírem os portfólios, sobre si e suas aprendizagens, revela a elas próprias e às docentes.

\section{METODOLOGIA - CONTEXTO E ORGANIZAÇÃO DOS DADOS}

Nessa investigação adotamos a pesquisa qualitativa, tendo em vista uma perspectiva dialógica e sócio-histórica da linguagem, já que entendemos que o 
sujeito se desenvolve ao se expressar (considerando neste caso as escritas de si e os diálogos) aos outros e a si mesmo - quando se coloca na posição de outro de si (BAKHTIN, 2010b; VOLÓCHINOV, 2017) - no meio em que vive. Dentro dessa abordagem optamos pelo estudo de caso, uma vez que a investigação centrava-se em um momento da aula (BODGAN; BIKLEN, 1994) - a construção de portfólios por vinte e três crianças, que compunham uma turma de primeiro ano de uma escola pública - com o objetivo de pesquisar uma situação também particular (LÜDKE; ANDRÉ, 1986): a escrita de si no portfólio como reveladora dos sentidos construídos pelas crianças no processo de ensino e aprendizagem, bem como reveladoras delas próprias e das práticas da professora.

Os portfólios foram construídos por um grupo de vinte e três crianças de seis e sete anos, de um primeiro ano do ensino fundamental, de uma escola pública do sistema municipal de ensino de uma cidade do interior de São Paulo. Uma vez por semana, os educandos, em quintetos, levavam tudo o que haviam produzido durante a semana para a biblioteca. Esse momento ocorria na companhia da pesquisadora, que acompanhava as aulas da turma duas vezes por semana. Ao se depararem com as suas produções, cada uma das crianças escolhia aquela que tinha mais significado ou a que mais havia gostado de realizar. Após eleger uma produção, pensavam sobre o porquê de suas decisões e escreviam essa justificativa (muitas vezes a pesquisadora era a escriba).

Inicialmente, a intervenção realizada para que as crianças elegessem uma produção era o enunciado: "Escolha a mais importante para você", seguida da pergunta "O que você aprendeu com essa que você escolheu, que a faz mais importante que as outras?". Contudo, percebemos que a intenção não era que os educandos elegessem, para compor o portfólio, a produção que julgassem ser a mais importante do ponto de vista da professora, mas sim a que fosse mais significativa para cada um deles. Com isso o enunciado passou a ser "Escolha a mais importante para você, seja porque gostou mais, porque aprendeu algo ou porque simplesmente a escolheu".

Após um período de três meses, tempo em que as crianças foram se apropriando da construção dos portfólios, realizamos uma entrevista semiestruturada com elas, com o intuito de compreender qual era a reflexão e a 
autoavaliação que as crianças faziam ao reverem tudo o que haviam colocado nos portfólios. O roteiro da entrevista consistia em compreender se o educando, ao retornar ao portfólio, percebia o que aprendeu durante o período em que esse instrumento foi construído; se enxergava o próprio desenvolvimento, notando o que fazia no início do portfólio e o que passou a alcançar no final dessa construção; e, além disso, foi perguntado se o portfólio e a sua construção auxiliavam na aprendizagem dele e como.

Para construir compreensões acerca da questão de investigação: o que os portfólios reflexivos revelam dos aprendizados das crianças?, notamos a possibilidade de organizar os dados a partir de eixos referentes às justificativas dos educandos em relação às suas escolhas (para alcançar os sentidos atribuídos pelas crianças); e através de eixos que dizem respeito aos diferentes temas das atividades eleitas para compor o portfólio (para compreensão dos sentidos atribuídos pelas crianças em relação às diferentes áreas dos conhecimentos também). Consideramos, portanto, tanto a área do conhecimento das propostas quanto o tipo de justificativa construída como aspectos importantes que podem revelar os sentidos que as crianças atribuem às propostas que realizam na escola. Neste artigo, contudo, nos deteremos às análises relacionadas às justificativas construídas pelas crianças e não às áreas do conhecimento das propostas eleitas.

Os eixos construídos para organizar e analisar os dados estão diretamente relacionados ao objetivo da pesquisa: alcançar o que revelam os educandos sobre si e suas aprendizagens ao escolherem suas produções para compor os portfólios e ao justificarem essas escolhas. A partir dos eixos pensados construímos o quadro 1, no qual cruzamos as informações referentes aos temas das propostas e às justificativas dadas pelas crianças.

Quadro 1:Temas das propostas e justificativas

(continua)

\begin{tabular}{|l|r|r|r|r|r|}
\hline Justificativa Propostas: & Artísticas & Alfabetização & Matemática Jogos & Total \\
\hline Porque gostei (fala o que gostou) & 10 & 26 & 4 & 1 & 41 \\
\hline Porque me ajudou (explica como) & 0 & 6 & 3 & 0 & 9 \\
\hline Porque eu aprendi (explica o que) & 17 & 53 & 18 & 2 & 90 \\
\hline Porque eu aprendi (não explica o que) & 0 & 3 & 0 & 0 & 3 \\
\hline
\end{tabular}


Atos de Pesquisa em Educação - ISSN 1809-0354

Blumenau, v.14, n.2, supl.1, p.772-791, out./nov. 2019

DOI: http://dx.doi.org/10.7867/1809-0354.2019v14n2s1p772-791

\begin{tabular}{|l|r|r|r|r|r|}
\hline Justificativa Propostas: & Artísticas & Alfabetização & Matemática & Jogos & Total \\
\hline Estabelece relação com o cotidiano & 7 & 8 & 3 & 0 & 18 \\
\hline Fiz a atividade sozinho (a) & 0 & 6 & 1 & 0 & 7 \\
\hline Realizei bem a atividade & 0 & 6 & 2 & 0 & 8 \\
\hline Treinei & 0 & 1 & 0 & 0 & 1 \\
\hline Notei a minha evolução & 1 & 3 & 0 & 0 & 4 \\
\hline Descreveu o que foi feito & 2 & 6 & 1 & 1 & 10 \\
\hline Total & 37 & 118 & 32 & 4 & 191 \\
\hline
\end{tabular}

Fonte: Arquivo próprio.

A partir da construção do quadro 1 pudemos realizar uma pré-análise, na qual comparamos de maneira sistemática os dados para, posteriormente, aprofundarmos as compreensões sobre a questão da pesquisa. Observamos que os trabalhos foram escolhidos por diferentes razões. Ao nos determos ao quadro foi possível perceber quais as razões expostas para a escolha dos trabalhos e a quantidade de cada um dos tipos de justificativa.

Após a construção do quadro, nomeamos e agrupamos as justificativas em categorias, a saber: autoavaliação, evidências dos sentidos atribuídos pelas crianças, reflexão acerca das relações entre conteúdo e cotidiano, metacognição e descrição da atividade. As categorias foram construídas a partir do que indicavam os dados, ou seja, partiram do que expressavam os sujeitos em seus portfólios.

Dentro da primeira categoria (autoavaliação) se encontram as justificativas descritas no quadro 1 como:

- Porque eu aprendi (diz o que),

- Porque eu aprendi (não diz o que),

- Realizei bem,

- Notei a minha evolução,

- Fiz sozinho.

Já, a segunda categoria (evidências dos sentidos atribuídos pelas crianças) comporta a justificativa:

- Porque eu gostei.

A terceira se refere às reflexões acerca do conteúdo e do cotidiano:

- Estabelece relação com o cotidiano. 


\section{Atos de Pesquisa em Educação - ISSN 1809-0354 \\ Blumenau, v.14, n.2, supl.1, p.772-791, out./nov. 2019 \\ DOI: http://dx.doi.org/10.7867/1809-0354.2019v14n2s1p772-791}

E a quarta, trata-se do exercício da metacognição, presente nas justificativas descritas como:

- Porque me ajudou (explica como).

Ademais, também há a presença de justificativas menos reflexivas, que vem a constituir a categoria descrição:

- Treinei,

- Descreve o que foi feito.

Os enunciados mais recorrentes, seja na conversa com as crianças, sejam aqueles emergentes nas entrevistas foram aqueles que se referem à autoavaliação (principalmente no quesito da percepção da aprendizagem de determinado conteúdo), seguidas pelos que se referem ao gosto que tiveram por realizar as proposta (sentidos atribuídos aos trabalhos), e pelos que as crianças estabeleceram uma relação com o cotidiano (capacidade reflexiva de estabelecer relações). Posteriormente, aparece a categoria que aborda as justificativas nas quais as crianças descreveram as propostas que realizaram e, por último, são as justificativas cuja característica central é a metacognição.

A organização dos dados pelo quadro, associada à construção de categorias, indicam os processos que ocorriam com as crianças durante a construção dos portfólios. Essa variedade de justificativas e tipos de reflexões indica que o portfólio "can be described as a portrait of the child, his or her skills, abilities and interests"3 (KANKAANRANTA, 1996, p. 4), que reflete não somente o desenvolvimento dos educandos, mas também seus interesses e os modos como organizam os pensamentos.

Assim que os dados foram produzidos e as categorias pensadas, organizaram-se dois eixos de análise. O primeiro foi denominado como reflexão discente, inclui o portfólio como uma construção que permite diversos tipos de reflexões, como mencionado anteriormente, e coloca o educando na posição de autor da sua aprendizagem. O segundo eixo, reflexão docente, contempla a construção do portfólio como algo que auxilia a professora a melhor conhecer seus alunos e o que pensam do ensino e da aprendizagem, bem como a realizar uma

\footnotetext{
${ }^{3}$ Tradução livre: pode ser descrito como um retrato da criança, de suas habilidades, capacidades e interesses.
} 
avaliação não só da aprendizagem das crianças, mas também do ensino que pratica, reorganizando, assim, sua prática a favor dos educandos.

\title{
4 ANÁLISES E DISCUSSÃO
}

\subsection{REFLEXÕES DISCENTES}

Bakhtin (2010a), ao explicar que os gêneros do discurso são tipos relativamente estáveis de enunciados, nos indica que existem gêneros primários e secundários. Enquanto os primeiros são aqueles que se formam na situação imediata, os gêneros secundários incorporam e reelaboram os primários. Isto é, os gêneros primários são aqueles que se dão nos acontecimentos da vida mais imediatos. Já, os gêneros secundários passam por uma reelaboração, como ele diz:

\begin{abstract}
Os gêneros discursivos secundários (complexos - romances, dramas, pesquisas científicas de toda espécie, os grandes gêneros publicísticos, etc.) surgem nas condições de um convívio cultural mais complexo e relativamente muito desenvolvido e organizado (predominantemente 0 escrito) - artístico, científico, sociopolítico, etc. No processo de sua formação eles incorporam e reelaboram diversos gêneros primários. (BAKHTIN, 2010a, p. 263)
\end{abstract}

Ao produzir algo a partir da reflexão sobre o vivido o sujeito dá um acabamento estético provisório ${ }^{4}$ (BAKHTIN, 2010a) ao acontecimento. É através desse acabamento provisório que a pessoa tem a possibilidade de se distanciar do que viveu e olhar para aquilo com uma outra exotopia (BAKHTIN, 20035), ou seja, com uma distância. É também essa distância que favorece que ela perceba aspectos do vivido que antes eram imperceptíveis.

A criança que, em sala de aula, constrói seu calendário individual, colocando todos os dias do mês, escrevendo quais os feriados e quais os aniversariantes do mês, pode ser que realize todo esse processo de maneira mais imediata. Essa

\footnotetext{
${ }^{4}$ Somos seres inacabados, sempre em transformação. No entanto, quando as crianças produziam o portfólio reflexivo, acabavam provisoriamente os momentos vividos e, nesse acabar provisório e estético, construíam compreensões para o anteriormente vivido.

${ }^{5}$ Neste artigo foram usadas duas edições do livro Estética da Criação Verbal, de Mikhail Bakhtin, uma vez que ambas possuem traduções diferentes. O conceito de exotopia (distância) é utilizado dessa forma somente na tradução de 2003, como o utilizamos aqui; também essa edição consta nas referências.
} 
mesma criança, quando escolhe o calendário como proposta significativa para compor o seu portfólio, de um lugar já distanciado, pensa sobre a razão de sua decisão, uma vez que the é solicitada uma justificativa. Ao refletir sobre suas razões expressa, para si e para os outros, sentidos muitas vezes não pensados anteriormente.

Nota-se esse movimento quando P. ${ }^{6}$, ao escrever, justifica ter escolhido o calendário pois sabe que está chegando o dia das crianças e o dia das professoras: "Escolhi essa atividade porque eu gostei de fazer. Foi legal porque eu fiz o dia das semanas e porque sei que está chegando o dia das crianças e o dia dos professores" (P. - indica os sentidos atribuídos e seus gostos/estabelece relação com o cotidiano). Ou quando M., ao eleger a mesma proposta, indica outra razão, ao expor que o calendário the é interessante porque o ajuda a saber o dia em que está: "Escolhi porque o mais interessante para mim é o calendário. $O$ dia de hoje é o mais importante, ele ajuda a saber o dia que é" (M. - Estabelece relação com o cotidiano).

A comparação das duas escolhas e suas razões podem indicar relevâncias à professora. Nem sempre a criança aprende o que a docente visa a ensinar. $O$ intuito dessa professora poderia ser ensinar como está dividido o tempo dentro do ano: em meses com trinta ou trinta e um dias geralmente e em semanas, que começam no domingo e terminam no sábado. No entanto, quando $M$. sinaliza que para ele a produção é importante pois sabe o dia que é hoje, ele indica outro saber, o de se localizar no tempo presente, ao visualizar o ontem e o amanhã. Da mesma maneira, quando $\mathrm{P}$. argumenta que sua escolha se deu porque quando construiu o seu calendário soube que no mês havia o dia das crianças e o dia dos professores, o que mostra é que essas datas são importantes para ele, bem como saber que elas estão próximas.

Conforme os próprios educandos revelam, o portfólio oportuniza

[...] evidenciar o fluir dos processos subjacentes ao modo pessoal como cada qual se apropria singularmente da informação, reconstruindo o seu conhecimento pessoal prévio, permite ao professor/formador compreender e intervir antecipadamente nesses mesmos processos (SÁ-CHAVES, 2005, p. 9).

\footnotetext{
${ }^{6}$ Os sujeitos da pesquisa serão identificados através da primeira letra do nome de cada um.
} 
Destarte, ao reconhecermos e entendermos o modo como os sujeitos constroem conhecimentos, as docentes podem se tornar capazes de intervir nesses processos e passar a levá-los em consideração na construção e na execução de sua prática de ensino, de modo que essas intervenções e reflexões sobre a própria prática sejam mudadas em prol de uma aprendizagem mais significativa para cada um dos discentes.

O mesmo ocorre com outras duas crianças que, ao elegeram uma dobradura do Saci Pererê que fizeram para compor o portfólio, argumentam: "Eu aprendi a fazer a dobradura. Agora posso fazer em minha casa" (J.- autoavaliação). "Eu gostei dessa porque aprendi que o Saci-Pererê é uma lenda" (C.- autoavaliação/indica seus gostos).

As relações e as reflexões que cada educando estabelece entre os conteúdos que the são ensinados e o que traz de repertório são singulares porque os sujeitos são singulares, têm vivências singulares e, por esse mesmo motivo, pensam de maneiras distintas. Essas singularidades e as próprias crianças são, muitas vezes, reveladas nas escolhas que fazem e nos porquês que narram ao construírem os portfólios. Enquanto para uma criança o que deu sentido à proposta foi o conceito de lenda e o personagem Saci-Pererê, para outra foi o trabalho manual de fazer a dobradura.

A escrita de si e das próprias aprendizagens dão pistas às docentes, pistas sobre como cada uma das crianças está se relacionando com o que produz em aula, sobre o que as motiva, sobre quais são as relações que estabelecem entre os conteúdos que aprendem e o que vivem e sobre como enxergam a própria produção. Afinal, a construção dos portfólios é

um processo que se tem como facilitador do auto-reconhecimento, [...] podendo em simultâneo evidenciar, sob a forma de produto final, um certo balanço de aprendizagens (ou de competências) que, por sua vez, se pode constituir como condição de novos tipos de reconhecimento (SÁ-CHAVES, 2004, p. 30).

Esse reconhecimento facilitado pelo portfólio, além de ser "auto" é, também, um reconhecimento do sujeito por outros sujeitos, uma vez que ele se expõe não somente nas escolhas, mas ainda nas argumentações que justificam essas escolhas. Dessa maneira, como indica Sá-Chaves (2004), os portfólios reflexivos 


\section{Atos de Pesquisa em Educação - ISSN 1809-0354 \\ Blumenau, v.14, n.2, supl.1, p.772-791, out./nov. 2019 \\ DOI: http://dx.doi.org/10.7867/1809-0354.2019v14n2s1p772-791}

possibilitam novos tipos de reconhecimento, não somente para os alunos em si, mas também para as professoras.

Além da criança fazer um movimento de relacionar o que aprende com o cotidiano, outro movimento interessante, que muitas vezes aparece nas justificativas, é o dela pensar sobre como aprende ou aprendeu algo. Y., ao escolher uma atividade de interpretação de texto para o seu portfólio, na qual precisava ler o texto, sublinhar algumas palavras que a professora pediu e assinalar duas respostas corretas, escreve: "Escolhi porque eu aprendi a ler e a escrever, eu fui lendo as letrinhas e juntando" (Y. - metacognição/autoavaliação).

A menina mostra o conhecimento sobre decodificação já elaborado por ela, pensa sobre os procedimentos que utiliza para ler e chega à percepção de que precisa juntar as letras para que tenham algum sentido no texto. Dessa forma, realiza uma reflexão sobre os mecanismos cognitivos necessários para desenvolver a atividade.

Outro dado é o da R., que elege uma atividade de sequência numérica. A atividade consistia em uma folha na qual havia quatro palhaços desenhados e, de cima de cada um saía uma barra dividida em oito partes, em cada uma das barras havia um número em uma das partes e a criança deveria completar o restante conforme o número já disposto, ou seja, colocando os numerais anteriores e posteriores. R., ao justificar a sua escolha, não fala em momento algum sobre a sequência numérica, sobre os números ou mais amplamente sobre a área da matemática, mas sobre esse trabalho ter sido a sua melhor pintura (autoavaliação).

A criança ao eleger um trabalho cuja pintura julga ser a melhor, estabelece critérios diferentes dos da professora para realizar a autoavaliação. Os alunos participam, portanto,

[...] da formulação dos objetivos de sua aprendizagem e avaliam seu progresso. Eles são, portanto, participantes ativos da avaliação, selecionando as melhores amostras de seu trabalho para incluí-las no portfólio (VILLAS BOAS, 2004, p. 38).

A perspectiva a ser olhada pela professora em uma proposta didática pode não ser a mesma perspectiva que uma criança adota ao observar o seu portfólio. É importante que os educandos estabeleçam critérios para analisar o próprio 


\section{Atos de Pesquisa em Educação - ISSN 1809-0354 \\ Blumenau, v.14, n.2, supl.1, p.772-791, out./nov. 2019 \\ DOI: http://dx.doi.org/10.7867/1809-0354.2019v14n2s1p772-791}

desenvolvimento e deem a ver quais são esses critérios às professoras, de maneira a revelar quais são as relações que eles estabelecem ao refletir sobre e ao avaliar os conhecimentos que vêm construindo.

Essa autoavaliação não ocorre somente no momento de voltar a todos os trabalhos realizados e eleger um dentre tantos. A autoavaliação também acontece quando o educando olha para o todo do seu portfólio, quando se atenta desde a primeira atividade que selecionou até a última, distribuídas no portfólio de maneira cronológica. Nesse momento as crianças percebem a evolução de suas aprendizagens. Durante as entrevistas semiestruturadas, ficou claro que esse ato de rever o portfólio possibilita que a criança se perceba em desenvolvimento, perceba que mudou e que aprendeu.

$\mathrm{Na}$ entrevista de F., ao ser questionada se conseguia perceber o que aprendeu ao olhar o seu portfólio, ela respondeu que aprendeu a ler, a escrever e muito sobre os bichos. Essa menina, quando indagada sobre o que pensava sobre a construção do portfólio, disse: "É bom porque a gente aprende um monte de coisa, a gente pensa que a gente faz mal pintado, mal escrito, que a gente não está aprendendo a ler, mas a gente está" (F. - autoavaliação).

F., através do portfólio, percebia o seu desenvolvimento, razão pela qual Villas Boas (2004) compara esse instrumento a um espelho no qual o educando percebe o seu crescimento e, sendo assim, pode ser um meio para construir uma autoconfiança.

\subsection{REFLEXÕES DOCENTES}

A partir do momento em que a docente tem acesso às propostas eleitas pelos educandos para compor os portfólios reflexivos e aos enunciados em que explicam essas escolhas, ela percebe o que mais atinge cada uma das crianças e como cada uma recebe as propostas.

Dessa maneira, considerando que nem tudo o que se ensina é aprendido e que o que é aprendido é aprendido de diversas maneiras diferentes da esperada pela professora, o aspecto avaliativo do portfólio deixa de ser somente voltado à aprendizagem e passar a ser voltado também ao ensino. Ou seja, esse aspecto 
deixa de existir somente pelo fato de a criança estar sendo avaliada pelo que deposita e diz em seu portfólio. $O$ aspecto avaliativo também age sobre outra perspectiva, a avaliação do ensino que a professora pratica, isso porque permite compreender quais ações intencionais de ensino potencializaram aprendizagens para cada criança e para o coletivo de crianças. Através da avaliação do ensino a professora tem melhores condições de refletir sobre os objetivos do seu trabalho e se esses estão sendo atingidos ou não.

A docente da turma em que a pesquisa foi realizada discorre que os portfólios Ihe possibilitaram uma reflexão e uma reorganização do trabalho, quando menciona, em entrevista semiestruturada com a pesquisadora, que a utilização dos portfólios Ihe possibilitou compreender como as crianças iam aprendendo. Diz que, dessa maneira, foi aprimorando o trabalho pedagógico, pensando, ainda, nas alterações que deveriam ou não ser feitas em sua prática para proporcionar avanços nas aprendizagens dos educandos.

À medida que a docente percebe que tipos de reflexão cada proposta está potencializando, quais atividades aparecem eleitas como as que as crianças mais gostaram e quais são os sentidos atribuídos a elas pelos educandos, a professora passa a se questionar sobre as potencialidades de suas propostas. Além de atingir quais tipos de propostas estão fazendo as crianças mobilizarem mais conhecimentos e desenvolverem estratégias para as realizarem e quais não estão, a professora também começa a conhecer e a entender melhor seus educandos, uma vez que através da escrita de si eles acabam expondo características, vontades e sentimentos.

S., por exemplo, - ao eleger para o portfólio uma proposta em que havia um pequeno texto e, logo abaixo, desenhos acompanhados de um espaço onde teria de escrever o nome dos desenhos logo após encontrar a palavra correspondente no texto - explica porque optou por essa: "Aprendi a escrever foguete, folha, foca, faca e flor. Gostei porque eu posso pintar e eu sou bom em pintar e fazer continhas" (S.autoavaliação/sentidos atribuídos).

Essa criança, que ainda não apresentava uma escrita alfabética, sentiu necessidade de expor, ademais da argumentação sobre a escrita, que era boa em outros campos dos conhecimentos. Esses indícios presentes nas escritas que as 
crianças fazem de si são de uma relevância ímpar para a professora entender como cada uma lida com os conhecimentos que estão sendo construídos e com as imagens que têm delas próprias.

Saber, portanto, quais propostas atingiram mais os educandos e a razão disso, assim como saber como as crianças se sentem nas relações estabelecidas com os conhecimentos, são fatores importantes para as docentes repensarem a prática de ensino e reorganizarem-se a favor das crianças.

\section{CONSIDERAÇÕES FINAIS}

Bakhtin, ao se referir ao texto em seu sentido mais amplo, ou seja, "qualquer conjunto coerente de signos", explica que os textos "são pensamentos sobre pensamentos, vivências das vivências, palavras sobre palavras, textos sobre textos" (2010a, p. 307). As escritas/falas das crianças que justificam cada escolha para compor o portfólio reflexivo se configuram como pensamento sobre pensamento.

O pensamento sobre pensamento, possível na construção do portfólio, vem a ser também uma resposta a si mesmo. A criança, ao refletir sobre a sua aprendizagem, coloca-se em um lugar diferente do lugar que ocupava quando realizou a proposta, dessa maneira tem acesso a um excedente de visão ${ }^{7}$ sobre si e sobre os modos como aprende.

Colocando-se nesse outro lugar, os educandos refletiam sobre o trabalho a partir de um outro tempo e um outro espaço. Ao elegerem as propostas e justificarem essa escolha, eles estavam pensando sobre suas produções, sobre o processo e o produto da realização dessas propostas, pensavam sobre os pensamentos que haviam tido ao realizar cada proposta. Assim, esses pensamentos sobre pensamentos, materializados na escolha e na escrita da justificativa (e também no portfólio), eram compostos também por: autoavaliações, sentidos que atribuíam às propostas, reflexões acerca das relações entre conteúdo e cotidiano, metacognições e descrições.

\footnotetext{
7 Quando o sujeito se coloca em um lugar diferente do que estava em determinada situação, acaba por ter outras percepções do mesmo acontecimento, possíveis justamente por estar situado em outro lugar. Esses aspectos, que o sujeito não tinha acesso antes, mas são perceptíveis a partir de um lugar distanciado, são denominados excedentes de visão (BAKHTIN, 2010a).
} 
Podemos afirmar que a proposta de construção de portfólios reflexivos vem a ser uma possibilidade de a criança construir novos conceitos (VIGOTSKI, 2008) e reflexões a partir do contexto que lhe é ampliado. Isso ocorreu conforme as crianças passaram, com maior frequência, a se deparar com situações em que necessitavam pensar sobre a sua aprendizagem e o seu trabalho escolar. Os conceitos espontâneos (adquiridos no dia a dia) e os não espontâneos (científicos) se relacionam e, mais, esses últimos se desenvolvem com a ajuda da atividade mental da criança (VIGOTSKI, 2008). A pesquisa indicou que a construção dos portfólios reflexivos, ao voltar a atividade mental da criança para a própria aprendizagem e para si mesma, potencializou a construção de pensamentos mais elaborados, de conceitos não tão espontâneos. Ao dizerem de suas opções, gostos e aprendizagens através das propostas escolares, as crianças relacionavam 0 conteúdo escolar com o seu dia a dia e pensavam sobre o próprio pensamento. Nesses movimentos, por vezes, atribuíam novos sentidos aos conteúdos escolares.

O pensamento/texto sobre pensamento/texto, mencionado por Bakhtin (2010a), não era apenas uma resposta que a criança elaborava para si própria, mas também uma resposta à professora. Isso porque a partir do que o educando responde, através do seu portfólio, acaba tornando possível à professora um excedente dela mesma em relação a própria prática. A partir do que lê nos portfólios, a docente tem possibilidade de perceber o que antes não havia notado, tanto em relação ao desenvolvimento do educando como em relação a sua prática, assim consegue avaliar e reorganizar o seu trabalho em função do que indicam as crianças sobre si mesmas e sobre o ensino que ela própria pratica.

Não podemos deixar de lembrar o diálogo como uma arena de vozes (SOBRAL, 2009), na qual os sujeitos se formam nas relações que estabelecem. Os portfólios revelaram as vozes das crianças, revelaram os sentidos que atribuíam aos seus próprios atos e às propostas da professora, evidenciaram as diferenças, as diferentes maneiras que o ensino chega para cada uma das crianças. É preciso escutar as crianças, alcançar os sentidos que dão ao ensino, entender como ocorre cada aprendizagem. Os portfólios reflexivos, como instrumentos mediadores (VIGOTSKI, 2007), ao revelarem as diferenças, as crianças e o que pensam e sentem em relação a si mesmas e às relações que estabelecem com os 
Atos de Pesquisa em Educação - ISSN 1809-0354

Blumenau, v.14, n.2, supl.1, p.772-791, out./nov. 2019

DOI: http://dx.doi.org/10.7867/1809-0354.2019v14n2s1p772-791

conhecimentos, se mostram como meios potentes para que as vozes das crianças estejam cada vez mais presentes e audíveis nessa arena de vozes.

\section{VANESSA FRANÇA SIMAS}

Doutora em Educação pela UNICAMP (Universidade Estadual de Campinas - Brasil) e pela UGR (Universidad de Granada - Espanha). Pesquisadora do GEPEC - Grupo de Estudos e Pesquisas em Educação Continuada. Professora da Educação Infantil na Prefeitura Municipal de Campinas.

\section{GUILHERME DO VAL TOLEDO PRADO}

Professor Livre-Docente da Faculdade de Educação da UNICAMP. Pesquisador e coordenador do GEPEC - Grupo de Estudos e Pesquisas em Educação Continuada.

\section{REFERÊNCIAS}

ALARCÃO, I. Professores reflexivos em uma escola reflexiva. São Paulo: Cortez, 2010.

BAKHTIN, M. Estética da criação verbal. 4. ed. São Paulo: WMF Martins Fontes, 2003.

BAKHTIN, M. Estética da criação verbal. 5. ed. São Paulo: WMF Martins Fontes, 2010a.

BAKHTIN, M. Para uma filosofia do ato responsável. São Carlos, SP: Pedro \& João editores, 2010b.

BODGAN, R.; BIKLEN, S. Investigação qualitativa em educação. Portugal: Porto Editora, 1994.

HERNÁNDEZ, F. Cultura visual, mudança educativa e projeto de trabalho. Porto Alegre: Artes Médicas Sul, 2000.

KANKAANRANTA, M. Self-Portrait of a Child: Portfolios as a means of SelfAssessment in Preschool and Primry School. (ERIC Document Reproduction Service № 403058). 1996. Disponível em: < http://files.eric.ed.gov/fulltext/ED403058.pdf>. Acesso em: 14 out. 2016.

LÜDKE, M.; ANDRÉ, M. Pesquisa em educação: abordagens qualitativas. São Paulo: EPU, 1986.

SÁ-CHAVES, I. Portfólios reflexivos: estratégias de formação de supervisão. Aveiro: Universidade, 2004. 


\section{Atos de Pesquisa em Educação - ISSN 1809-0354 \\ Blumenau, v.14, n.2, supl.1, p.772-791, out./nov. 2019 \\ DOI: http://dx.doi.org/10.7867/1809-0354.2019v14n2s1p772-791}

SÁ-CHAVES, I. Os portfólios reflexivos (também) trazem gente dentro: reflexões em torno do seu uso na humanização dos processos educativos. Porto: Porto Editora, 2005.

SHORES, E.; GRACE, C. Manual do Portfólio: um guia passo a passo para o professor. 7. ed. Porto Alegre: Artmed, 2001.

SOBRAL, A. Do dialogismo ao gênero: as bases do pensamento do círculo de Bakhtin. Campinas, SP: Mercado de Letras, 2009.

VIGOTSKI, L. Formação social da mente: o desenvolvimento dos processos psicológicos superiores. 7. ed. São Paulo: Martins Fontes, 2007.

VIGOTSKI, L. Pensamento e linguagem. 4. ed. São Paulo: Martins Fontes, 2008.

VILLAS BOAS, B. M. F. Portfólio, avaliação e trabalho pedagógico. 5. ed. Campinas, SP: Papirus, 2004.

VILLAS BOAS, B. M. F. O portfólio no curso de pedagogia: ampliando o diálogo entre professor e aluno. Educ. Soc., v. 26, n. 90, p. 291-306, jan./abril 2005.

VOLÓCHINOV, V. Marxismo e filosofia da linguagem: problemas fundamentais do método sociológico na ciência da linguagem. São Paulo: Editora 34, 2017.

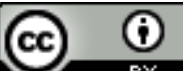

Esta obra está licenciada com uma Licença Creative Commons Atribuição 4.0 Internacional 